\title{
ICE DIVIDE MIGRATION AT BLUE GLACIER, U.S.A.
}

\author{
by
}

\author{
E.D. Waddington
}

(Geophysics Program AK-50, University of Washington, Seattle, WA 98195, U.S.A.)

and

\section{R.T. Marriott}

(Department of Atmospheric Sciences, AK-40, University of Washington, Seattle, WA 98195, U.S.A.)

\begin{abstract}
A 1984 strain net on the Snowdome of Blue Glacier showed that the surface slope is a good estimator of ice flow direction and divide location. Topographic maps from 1939, 1952, 1957, 1979, and 1984 show that the flow divide migrates within a zone up to $350 \mathrm{~m}$ wide, in response to changes in east-west gradient in snowfall. This zone encloses $6 \%$ of the Blue Glacier accumulation area and up to $10 \%$ of the year-end residual snow. An ongoing 28-year mass-balance study has used an extreme, westerly divide, giving systematically high net balance estimates. The correct catchment area, for a given balance year calculation, depends on the future migration sequence of the ice divide, with a time constant of about 30 years.
\end{abstract}

\section{INTRODUCTION}

LaChapelle $(1959,1965)$ described the Blue Glacier on Mt. Olympus, Washington State, U.S.A. Direct measurement of mass balance, i.e. ablation rate and residual snow depth, has been continued since 1957. The combination of spatial coverage and long record is nearly unique in North America. Statistically significant tests will soon be possible for relations between glacier mass balance and hydrological or meteorological measurements (Tangborn, 1980) and between mass balance and terminus position (Nye, 1965). Winter precipitation is high (exceeding $10 \mathrm{~m}$ snow accumulation), due to Pacific storms, and summer ablation is high, due to the low elevation $(2300 \mathrm{~m}$ to $1300 \mathrm{~m})$. The mass-balance data are being reduced to a standard format and a balance atlas is in preparation.

The Blue Glacier has two catchment areas. The northernmost, called Snowdome, is separated from the Black Glacier catchment area by an ice divide (Figure 1). The exact location of this divide must be known for the ongoing mass-balance study. Prior to 1984, the surface velocity on Snowdome had not been measured. LaChapelle (1965) estimated the divide position by assuming that ice flowed in the direction of the surface gradient on a 1957 topographic map (American Geographical Society, 1960). His estimate followed the steepest ascent line from the Pointer Rocks to the Bergschrund.

\section{SURFACE VELOCITY SURVEY}

To check the accuracy of LaChapelle's method, a strain net was established in the summer of 1984. Because of high ablation, stakes were reset weekly. The high accumulation would bury stakes in one year. Therefore the network was resurveyed within one season. Sliding on the lower glacier is less than $10 \%$ of the total motion (Engelhardt and others, 1978). If this is true on Snowdome, our summer velocity is close to annual velocity.

The displacements between July 7 and September 13 were determined, using a theodolite and an Electronic Distance Meter (EDM) at a point on Panic Peak (Figure 2)

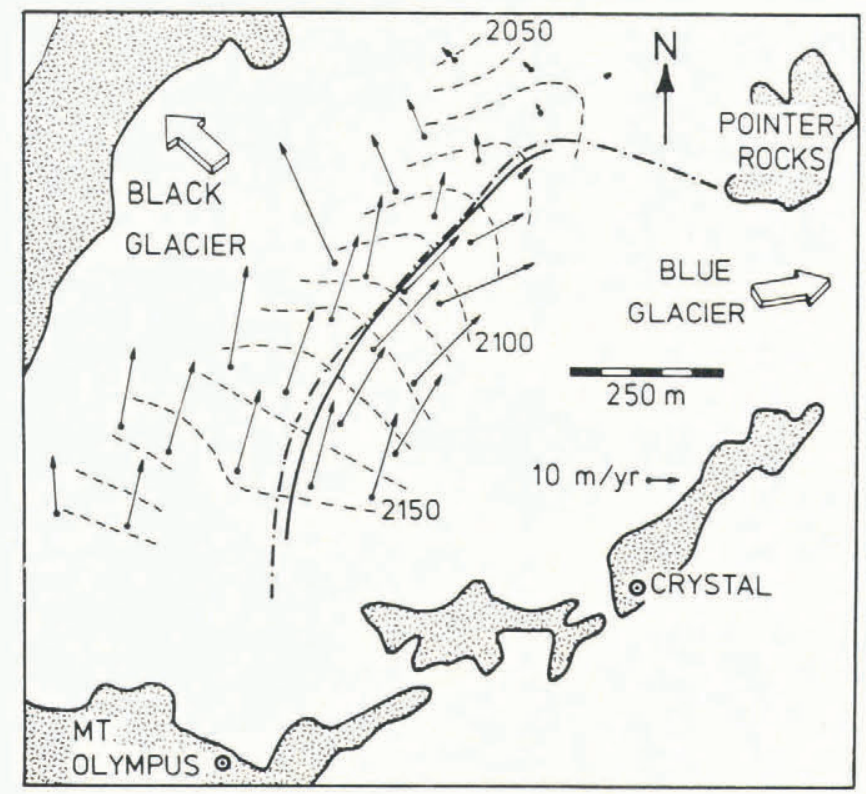

Fig.1. Stake velocities, and surface elevation (meters) in July, from 1984 strain net. Solid curve is flow divide derived from velocities. Broken curve is derived from surface gradient. Stippled areas are exposed bedrock.

and a horizontal reference marker pole on Crystal Peak. The maximum position error in each survey was $\pm 2 \mathrm{~cm}$; errors in the velocity are less than $\pm 20 \mathrm{~cm} \mathrm{a} \mathrm{a}^{-1}$. These velocities are shown in Figure 1, with the surface topography from the July survey.

\section{RESULTS}

The surface velocity vectors appear to follow the surface gradient closely. The divide found by interpolating the measured velocities agrees, to within $25 \mathrm{~m}$, with the steepest ascent path on the July contour map, implying that LaChapelle's method is appropriate. However, the 1984 divide lies up to $350 \mathrm{~m}$ east of its 1957 position.

Other maps, at 1:5000 with $5 \mathrm{~m}$ contours, based on aerial photography, exist for the years 1939, 1952, and 1979, with ground baseline checks for all but 1979. In Figure 2, we estimated the divide locations by LaChapelle's method for each of these maps. The uncertainty in these estimates increases from zero at the Pointer Rocks to $\pm 30 \mathrm{~m}$ at the bergschrund.

There appears to be a divide zone $50 \mathrm{~m}$ to $350 \mathrm{~m}$ wide, across which the divide migrates. Its area exceeds $0.12 \mathrm{~km}^{2}$. It accounts for about $6 \%$ of the accumulation 


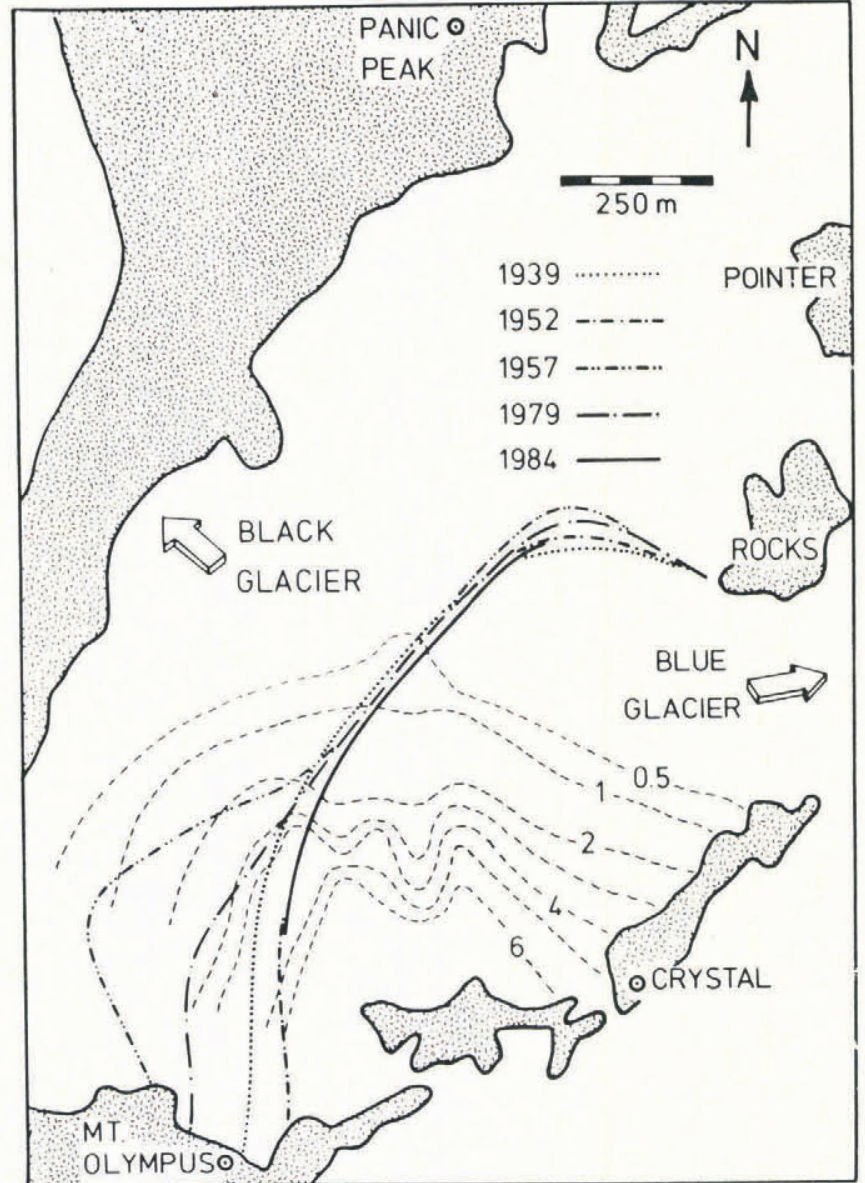

Fig.2. Flow divide on Snowdome, estimated by steepest ascent path from Pointer Rocks on contour maps for the years indicated. Dashed contours are residual snow depth (meters) in September 1979, a low balance year, but a pattern typical since mid 1970's.

area in a typical year and up to $10 \%$ of the year-end residual snow. The associated errors in net balance can be significant. All balance calculations to date used the 1957 divide, which occupied an extreme western position; the Blue Glacier net balance has been systematically overestimated. Accurate assessment of the errors introduced by the divide location will be possible with the updated data base in preparation.

\section{MECHANISM OF DIVIDE MIGRATION}

Ablation is uniform across the Snowdome. However, prevailing south-west winds of winter storms interact with the generally north-south ridge, to create an east-west gradient in snowfall on upper Snowdome. The magnitude and sign of the gradient depend on total snowfall and on temperature and wind speed, in a complicated way. The 1979 pattern (Figure 2), with residual snow depth increasing eastward, has been typical since the mid 1970's or earlier. With this pattern, a series of high-snowfall winters preferentially builds up the Blue Glacier side of the dome causing the crest to move east. In 1979, following dry winters in 1977, 1978, and 1979, the divide was to the west (Figure 2). In 1984, after high snowfall in 1982, 1983, and 1984 , the divide shifted to the east.

There is some evidence (LaChapelle, 1959; Davey, 1962) that the residual snow depth decreased to the east in the 1950's, lowering the Blue Glacier side, in spite of above-average balance. This caused the strong westward shift of the divide between 1952 and 1957.

The divide migration is strongest on the upper Snowdome, where the snow depth gradient (Figure 2) is normal to the divide. Lower down, the gradient turns parallel to the divide; the divide zone is narrowest here. Above Pointer Rocks, the divide turns and is again normal to the gradient; the divide again migrates.

\section{IMPLICATIONS}

With the recent snowfall pattern, divide migration tends to make the Blue Glacier less sensitive to climate fluctuations, while making the Black Glacier more sensitive. During successions of low snowfall years, the Blue captures catchment area from the Black. In high snowfall periods, the reverse occurs.

The flow divide can apparently move tens of meters each year, in response to short term climate fluctuations. This is of the same order as the ice flow velocity parallel to the divide (Figure 1) and much larger than the flow normal to the divide. A given parcel of ice in the divide zone may find itself alternately in the Blue Glacier or the Black Glacier drainage area, as the divide moves. Consider the portion of an annual layer deposited in the divide zone. The fraction of this mass which ultimately flows to the Blue Glacier depends on the divide migration sequence after deposition. An analysis (in preparation) of flow near a migrating divide shows that a time constant for this dependence is about 30 years. The flow divide at deposition is not a reliable estimator of the catchment limit for balance calculations. The correct catchment limit depends on future climatic events.

Using an average divide position for all balance years is also not correct. Extremes of net balance, occurring in years when the divide was far from its average position, would introduce errors into the budget calculations.

The divide position and the gradient of the residual snow depth should be observed carefully in future to achieve accurate mass-balance estimates.

\section{ACKNOWLEDGEMENTS}

This work was supported by NSF Grant No. DDP-8412641. A. Fountain provided topographic maps and his preliminary specific balance history. We thank all those who helped with the balance and velocity surveys.

\section{REFERENCES}

American Geographical Society 1960 Nine glacier maps: northwestern North America. American Geographical Society. Special Publication 34

Davey A 1962 Changes in Blue Glacier, Mount Olympus, Washington. Ohio State University. Institute of Polar Studies. Report 1

Engelhardt H F, Harrison W D, Kamb B 1978 Basal sliding and conditions at the glacier bed as revealed by bore-hole photography. Journal of Glaciology 20(84): 469-508

LaChapelle E 1959 Annual mass and energy exchange on the Blue Glacier. Journal of Geophysical Research 64(4): 443-449

LaChapelle E 1965 The mass budget of Blue Glacier, Washington. Journal of Glaciology 5(41): 609-623

Nye J F 1965 A numerical method of inferring the budget history of a glacier from its advance and retreat. Journal of Glaciology 5(41): 589-607

Tangborn W 1980 Two models for estimating climate-glacier relationships in the North Cascades, Washington, U.S.A. Journal of Glaciology 25(91): 3-21 